\title{
KEDUDUKAN HADITH DALAM BUKU “ DOA-DOA MUSTAJAB HARIAN YANG DI PETIK DARIPADA HADITH DAN AL-QURAN: KAJIAN TAHRIJ HADITH
}

\author{
Nor Bazila Shafie dan Mohd Arif Nazri \\ Jabatan Pengajian Al-Quran Dan As-Sunnah, Fakulti Pengajian Islam \\ Universiti Kebangsaan Malaysia, 43600 UKM Bangi Selangor, Malaysia. \\ norbazilashafie@ymail.com dan mohdarif@ukm.edu.my
}

\begin{abstract}
:
Takhrij is an important method in hadith studies and one of the methodologies used by hadith scholar to determine the position of hadith issued to know the source and the status of hadith either maqbul or mardud. There are 101 dua' from hadith found, with unknown specified source and status. The objective of this research is purposely to reveal both the validity and to rereview the status of hadith by takhrij means. The methodology used for this research is qualitative by analyzing each hadith with referring to original and authorized scriptures in order to determine the authentic sources as well as the status of the hadiths. In conclusion, $51 \%$ of the hadiths consist of hadiths maqbul, while $47 \%$ of hadiths are mardud, the rest $2 \%$ is irrelevant. This study provides the contribution for hadith researchers and communities in practicing the daily dua' sourced authentic hadith.
\end{abstract}

Keywords: Status Hadith, Doa Mustajab, Takhrij Hadith.

\section{Pendahuluan}

Kajian ini berkisarkan kedudukan hadith dalam Buku " Doa-doa Mustajab Harian yang Dipetik Daripada Hadith dan al-Quran”. Doa-doa yang terkandung dalam buku ini diambil dalam majalah Pengasuh terbitan Majlis Agama Islam Kelantan. Buku ini dicetak pada tahun 1991 oleh Percetakan Watan Sdn Bhd yang diedarkan secara percuma.

Doa merupakan senjatan dan satu ibadah yang dituntut dalam islam kepada semua umat Islam. Doa juga merupakan penghubung antara hamba 
dengan penciptanya(Allah).Ini bertetapan dalam ayat al-Quran yang mengalakkan Umat Islam berdoa. Firman Allah Taala:

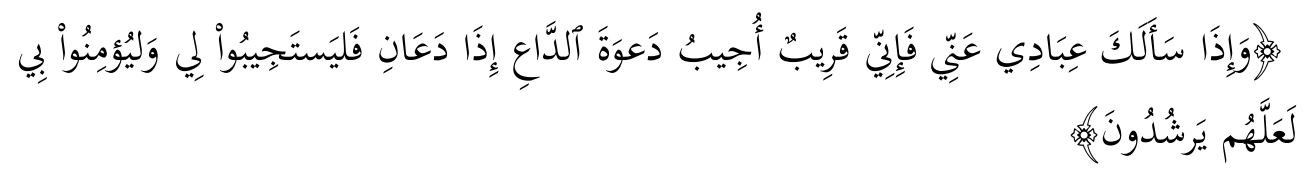

Maksudnya: Dan apabila hambaku bertanya kepadamu mengenai aku, maka, (beritabu kepada mereka)sesunggubnya aku (Allah) sentiasa hampir (kepada mereka); aku perkenankan permohonan orang yang berdoa apabila ia berdoa kepadaku. Maka hendaklah mereka menyahut (dengan mematubi perintabku), dan hendaklah mereka beriman kepada aku sampai mereka menjadi baik serta betul. ${ }^{1}$ (Surah al-Baqarah 2:186).

Menurut Ibn Qayyim, doa terbahagi kepada dua bahagian iaitu i) doa yang merupakan puji-pujian serta ibadat ii) doa yang merupakan permintaan atau permohonan ${ }^{2}$. Ini dapat disimpulkan bahawa bentuk dan lafaz doa sangat meluas, sebahagiannya merupakan puji-pujian, tasbih, takbir dan sebagainya.

Doa ataupun zikir yang lebih afdal adalah ayat suci al-Quran kerana ia merupakan sumber syariat Islam yang pertama. Al-Quran adalah kalam Allah yang diturunkan kepada Rasulnya Muhammad SAW untuk memberi petunjuk kepada umat Islam daripada kesesatan. Selain itu, banyak juga doa atau zikir yang diambil dan dijadikan amalan daripada hadith. Ini kerana hadith merupakan sumber Islam yang kedua selepas al-Quran. Terdapat banyak hadith Rasullulah SAW mengajarkan kepada kita lafaz doa yang pelbagai dan harus diamalkan, diikuti dan menjadi teladan supaya tidak ada penyelewengan dalam berdoa daripada segi bahasa dan cara yang tidak sesuai ${ }^{3}$.

Namun, kita digalakkan untuk berdoa dengan memohon apa sahaja yang diinginkan. Namun, terdapat juga doa yang dilarang daripada dihajati iaitu memohon sesuatu kejahatan dan keburukan pada diri sendiri, keluarga, anak-

\footnotetext{
${ }^{1}$ Semua terjemahan ayat al-Qur'an dalam tulisan ini berdasarkan Tafsir Pimpinan al-Qur'an kepada Pengertian al-Qur'an, edisi keenam, (Kuala Lumpur: Bahagian Hal Ehwal Islam, Jabatan Perdana Menteri, 1983). [Semua terjemahan ayat al-Qur'an dalam tulisan ini dibuat oleh penulis kecuali kalau dinyatakan sebaliknya.]

2 Abu Dayf al-Muduniy.Doa Munajat Para Nabi. (Kuala Lumpur: Al-Hidayah Publisher, 1997), hlm.17.

${ }^{3}$ Azharuddin Sahil.Doa Makbul atan Tertolak. (Kuala Lumpur: Utusan Publications \&

Distibutors Sdn Bhd, 2002), hlm.124/125.
} 
anak dan sebagainya ${ }^{4}$. Selain itu, tidak memohon sesuatu yang diluar kemampuan sebagai manusia atau sesuatu yang mustahil kita capai. Ini adalah salah satu sebab-sebab doa kita tertolak ${ }^{5}$.Sebaliknya, kita dianjurkan untuk memohon sesuatu yang baik untuk diri sendiri serta untuk orang lain dan memohon sesuatu yang tidak bertentangan dengan al-Quran

Buku ini dipilih kerana menghimpunkan doa-doa harian yang dipetik daripada hadith dan al-Quran yang digunakan dan diamalkan oleh masyarakat walaupun telah dicetak beberapa tahun yang lalu terutamanya masyarakat sebelum ini yang telah menggunakan buku tersebut, dan terdapat cetakan yang terbaru yang telah dijual kepada masyarakat, ini menunjukkan bahawa buku doa-doa harian masih diguna pakai oleh masyarakat. Maka, buku ini memerlukan kajian dalam penelitian semula tentang sejauh mana kesahihan hadith tersebut yang dijadikan doa melalui kaedah takhr $\vec{j}$ dan kajian ini juga bertujuan bagi mencadangkan penambahbaikan buku tersebut.

Namun, jika doa yang petik daripada hadith ini merupakan hadith yang bertaraf daif, tidak bermakna ia tidak boleh diamalkan selagi ia bertetapan dan tidak melampau makna al-Quran dan hadith serta membawa makna doa yang baik. Namun, apabila sesuatu itu telah disandarkan pada hadith daripada Nabi Muhammad SAW maka, ianya mestilah sahih darinya. Walau bagaimanapun, ulama telah memberi pelbagai pandangan dalam memberi hukum mengamalkan hadith yang bertaraf $d a^{c} \ddot{I}^{6}$

Kajian ini menggunakan kaedah reka bentuk kualitatif analisis kandungan dan menggunakan pengumpulan data melalui literasi kepustakaan dan kandungan teks. Pengkaji juga akan mengumpul doa-doa harian yang dipetik daripada hadith. Selepas mengumpul dan mengenal pasti hadith-hadith, pengkaji akan menilai kedudukan hadith tersebut melalui kaedah takhrï terhadap hadith-hadith yang dijadikan doa-doa mustajab harian untuk mengetahui hukum hadith sama sabih, hasan atau $d a \mathfrak{c} \mathbb{y}$.

\footnotetext{
${ }^{4}$ Abu Dayf al-Muduniy. Doa Munajat Para Nabi. (Kuala Lumpur: Al-Hidayah Publisher, 1997) hlm.65.

${ }^{5}$ Azharuddin Sahil. Doa Makbul atau Tertolak. (Kuala Lumpur: Utusan Publications \&

Distibutors Sdn Bhd, 2002) hlm.66.

${ }^{6}$ Muhammad Abu al-Laith al-Khair Abadi. 2009. Ulum Hadith. (Darul Syakir, 2009) hlm.156160
} 
Hadith adalah salah satu sumber rujukan yang kedua selepas al-Quran dan menjadi pegangan kepada umat Islam, sebagaimana sabda Rasulullah SAW di dalam hadis :

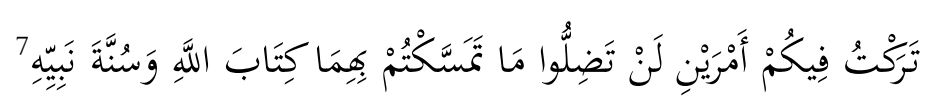

Maksudnya: Aku telah tinggalkan kepada kamu semua dua perkara. Kamu tidak akan sesat selama kepada keduanya, (iaitu) Kitab Allah dan Sunnah Rasul-nya.

Berdasarkan hadith di atas, jelaslah bahawa sesungguhnya manusia itu akan sentiasa berada di landasan Islam yang sebenar dan tidak akan sesat selagi mana mereka berpegang kepada al-Quran dan Sunnah yang betul dan sahih.

Seperti yang diketahui, doa atau zikir merupakan senjata bagi umat Islam dalam kehidupan mereka sehingga keutamaan berdoa atau zikir kepada Allah $\mathrm{Ta}^{\mathrm{c}}$ ala telah disebut di dalam al-Quran menerusi surah al-Baqarah ayat 152:

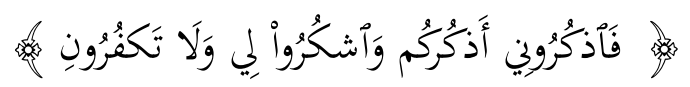

Maksudnya: Ingatlah kamu kepadaku( dengan mematubi bukum dan undangundangku) sampai aku membalas kamu dengan kebaikan dan bersyukurlah kamu kepadaku dan janganlah kamu kufur ( akan nikmatku). ".(Tafsir Pimpinan al-Rahman, 1983). ${ }^{8}$

Kebanyakan doa-doa atau zikir diambil daripada al-Quran dan Hadith yang dijadikan panduan dan amalan harian manusia bagi mendapat ganjaran daripada Allah Tacala. Seperti dalam buku "Himpunan Doa Mustajab" oleh Syeikh Ahmad Abd. Jawad, " Doa-Doa dalam al-Quran” oleh Ahmad Kamal Wong dan sebagainya yang memuatkan dan menghimpunkan doa-doa yang diambil daripada al-Quran dan hadith.

Terdapat banyak kajian yang berkaitan mentakhrij hadith sama ada hadith yang berkaitan doa-doa, ibadah, akidah dan sebagainya. Antara contohnya dalam Jurnal "Hadith Masyhur Dalam Masyarakat Melayu: Takhrij Dan Analisis" oleh Jawiah Dakir(2009). Selain itu juga, Terdapat 3 kajian di Universiti Kebangsaan Malaysia yang mengkaji kitab 40 Hadis Membudayakan al-

\footnotetext{
${ }^{7}$ Imam Malik, Munatta' Imam Malik, Kitab al-Qadr, Bab Larangan Ucapan Qadar. No: 3

8 Semua terjemahan ayat al-Qur'an dalam tulisan ini berdasarkan Tafsir Pimpinan al-Qur'an kepada Pengertian al-Qur'an, edisi keenam, (Kuala Lumpur: Bahagian Hal Ehwal Islam, Jabatan Perdana Menteri, 1983). [Semua terjemahan ayat al-Qur'an dalam tulisan ini dibuat oleh penulis kecuali kalau dinyatakan sebaliknya.]
} 
Sunnah yang terdapat 3 siri iaitu kajian pada tahun 2012 oleh Ahmad Mujahideen Bin Haji Yusoff yang bertajuk " Takhr $\not{y}$ dan Taliq Hadis di dalam Kitab 40 Hadis Membudayakan al-Sunnab Siri ke-2, dan Wan Khairul Aiman Bin Wan Mokhtar yang bertajuk "Takbrij dan Ta'liq Hadis di dalam Kitab 40 Hadis Membudayakan al-Sunnah Siri ke-4.Selain itu, kajian ini diteruskan oleh Wan Azlee Bin Wan Ibrahim, 2014 " Kedudukan Hadis Dalam Kitab 40 Hadis Membudayakan al-Sunnah ( Siri Ketiga) Jabatan Agama Johor. Tujuan utama kajian di atas dijalankan untuk mengenal pasti sumber serta hukum atau status hadith bagi memberi kepercayaan kepada pembaca atau masyarakat yang fgkmenggunakan kitab tersebut tanpa ragu-ragu serta menjadikan kitab tersebut sebagai kitab yang berautoriti.

Namun, kajian ini, "Kedudukan Hadith Dalam Buku Doa-doa Mustajab Harian yang Dipetik Daripada Hadith dan al-Quran" yang diambil dalam majalah Pengasuh terbitan Majlis Agama Islam Kelantan merupakan kajian yang menilai kedudukan hadith tersebut melalui takhrij hadith untuk mengetahui sumber dan hukum hadith sama ada maqbül atau mard $\bar{u} d$. Ini bertujuan untuk memberi maklumat kepada pembaca mengenai kedudukan hadith dalam setiap doa-doa tersebut sekaligus memberi kepercayaan kepada mereka dalam mengamalkan doa-doa tersebut serta meningkatkan kredibiliti sesebuah buku untuk diguna pakai sepanjang masa.

\section{Metode Kajian}

Pemilihan metode kajian yang betul dan tepat adalah sangat penting untuk memastikan kajian ini dijalankan dengan lancar. Justeru, pengkaji memilih metodologi reka bentuk kualitatif berbentuk kajian kepustakaan atau analisis kandungan. Walau bagaimanapun, terdapat dua metode yang diperlukan di dalam kajian ini iaitu metode pengumpulan data dan metode menganalisis data.

\section{a. Metode Pengumpulan Data}

Pengkaji menggunakan beberapa instrumen yang penting untuk mendapatkan dan mengumpulkan data yang tepat. Bagi mencapai objektifobjektif kajian seperti di atas, antara metode pengumpulan data yang digunakan adalah seperti berikut: Literasi kepustakaan: dalam kajian ini, pengkaji menggunakan kajian kepustakaan yang mana menggunakan buku-buku thurat sebagai rujukan yang utama seperti kitab Tis'ah dalam mengkaji hadith-hadith tersebut sebagai contoh: Sahîh Bukhārī, Sahīh Muslim, Sunan Abī Dawūd, 
Sunan al-Tirmidhī, Sunan al-Nasā'ī dan Sunan Ibn Majah, Musnad Darimi, Muwatta Malik dan Musnad Ahmad Ibn Hanbal. Selain itu, pengkaji akan merujuk kepada kitab lain jika tidak terdapat dalam kitab Tis ${ }^{c} a h$ seperti Sahỉh Ibn Hibban, Mustadrak al-Hakim dan sebagainya. Selain itu juga, Pengkaji juga menggunakan kaedah kandungan teks untuk mengumpul data yang diperoleh melalui kandungan teks dan sebagainya yang mana mampu dilihat didengar dan diterjemahkan.

Kaedah takhrij hadith yang digunakan dalam kajian ini ialah:

1. Penggunaan Perisian Jawāmi ${ }^{c}$ al-Kalim: Perisian hadith dalam Jawāmic Kalim adalah merupakan salah satu kaedah pencarian yang penting dan cepat serta memudahkan pengkaji kerana perisian di dalamnya lebih luas dan banyak. Dalam perisian ini, pengkaji hanya perlu mengenal pasti perkataan pada matan hadith untuk dijadikan sebagai "keyword" atau kata kunci untuk mendapatkan hadith. Perisian ini digunakan tujuan ini dilakukan hanya untuk membantu mencari dan mendapatkan sumber hadith, namun, pengkaji merujuk kepada kitab-kitab asal terhadap hadith-hadith tersebut. Pengkaji banyak menggunakan perisian ini bagi memudahkan pencarian hadith ini kerana ianya merupakan perisian yang sangat baik dan maklumat yang begitu mendalam.

2. Penggunaan Perisian hadith Maktabah al-Syamilah: Penggunaan Perisian hadith Maktabah al-Syamilah adalah sama seperti pencarian dalam perisian Jawāmic Kalim dan tidak banyak perbezaan dalam keduanya. Walau bagaimanapun, pengkaji tetap merujuk kepada kitab-kitab asal terhadap hadith-hadith tersebut.

3. Penggunaan Perisian di Internet: Selain itu juga, terdapat teknologi yang menggunakan internet yang menyediakan ruangan pencarian dan mendapatkan hadith yang menjadi rujukan kepada pengkaji kepada beberapa laman web hadith yang berautoriti yang kebanyakannya adalah daripada laman web berbahasa Arab. Antara laman web yang menjadi rujukan ialah www.islamweb, www.dorar.net,. Perisian ini memudahkan pencarian hadith sama seperti perisian sebelum ini. Namun, pengkaji juga akan merujuk semula kepada kitab-kitab asal dalam mendapatkan sumber dan hukum setiap hadith. 
Setelah maklumat dan data telah dikumpulkan daripada pelbagai sumber, penulis menggunakan metode analisis kandungan dalam menganalisis serta mengolah data-data tersebut dalam kajian ini. Terdapat tiga bentuk analisis data yang digunakan dalam kajian ini iaitu:

1. Metode Induktif: satu kaedah membuat kesimpulan daripada beberapa data yang bersifat umum, namun, kaedah ini digunakan untuk menjelaskan sesuatu dengan gambaran yang menyeluruh. Kaedah ini digunakan dalam kajian ini bagi menentukan sumber rujukan hadith dengan menjelaskan sumber asal setiap hadith melalui takhrij hadith.

2. Metode Kompratif/Perbandingan: merupakan kaedah yang membuat kesimpulan berdasarkan perbandingan data-data yang diperoleh oleh pengkaji semasa membuat kajian. Kaedah ini diaplikasikan dalam menentukan status perawi dengan membuat perbandingan ulama Ulama Jarh wa $T a^{c}$ dil dalam menghukumkan perawi tersebut. Selain itu, dalam menetapkan dan memilih status atau hukum hadith, penulis akan mengemukakan pandangan dan pendapat ulama mutaqaddimin dan kontemporari dan memilih mengikut pendapat yang Jumhur.

3. Rajah: metode ini memberikan gambaran yang lebih jelas dan memberi kefahaman yang mudah kepada pembaca. Kaedah ini digunakan dalam membuat aliran sanad ( shajaratu al-Asanid) dalam riwayat hadith supaya lebih jelas jalan atau jalur sanad dalam sesebuah hadith tersebut sama ada bertaraf sahih, hasan, atau dacif.

\section{b. Analisis Terhadap Kedudukan dan Hukum Hadith}

Setelah melakukan kajian, analisis terhadap kedudukan dan hukum hadith terdapat beberapa hadith yang berkedudukan maqbul dan mardud serta bukan berkenaan, hadith yang berkedudukan maqbül termasuk hadith yang sabih iaitu sabih al-Bukhārīidan Muslim serta sahih selainnya serta hadith yang bertaraf hasan. Manakala, hadith yang berkedudukan mard $\bar{u} d$ pula iaitu hadith yang bertaraf $d a^{c} \vec{i} f^{\prime}$ dan $d a^{c} \overline{i f} J i d d a n$ dan bukan berkenaan pula ialah doa yang bukan daripada hadith, akan tetapi doa yang diambil daripada potongan ayat al-Quran dan sejarah(hikayat) daripada sumber Tārikh Damsyiq oleh Ibn ${ }^{\mathrm{c} A s a ̄ k i r . ~}$ Berikut adalah gambaran hadith dalam kajian ini.

\section{Kedudukan Hadith}

(1) Maqbül 
Sebanyak 51\% hadith yang dikategori sebagai hadith yang maqbül yang mana terdiri daripada sabih termasuk sabih dalam Bukhārī dan Muslim serta hasan.

(2) Mardüd

Sebanyak 47\% hadith yang dikategori sebagai hadith yang Mard $\bar{u} d$ yang mana terdiri daripada $d a^{c} \bar{i} f$ dan $d a^{c} \bar{i} f$ Jiddan.

(3) Bukan berkenaan

Sebanyak 2\% doa yang bukan berkenaan iaitu bukan daripada hadith.

Berikut adalah rajah bagi menggambarkan dengan jelas dalam kedudukan hadith dalam kajian ini:

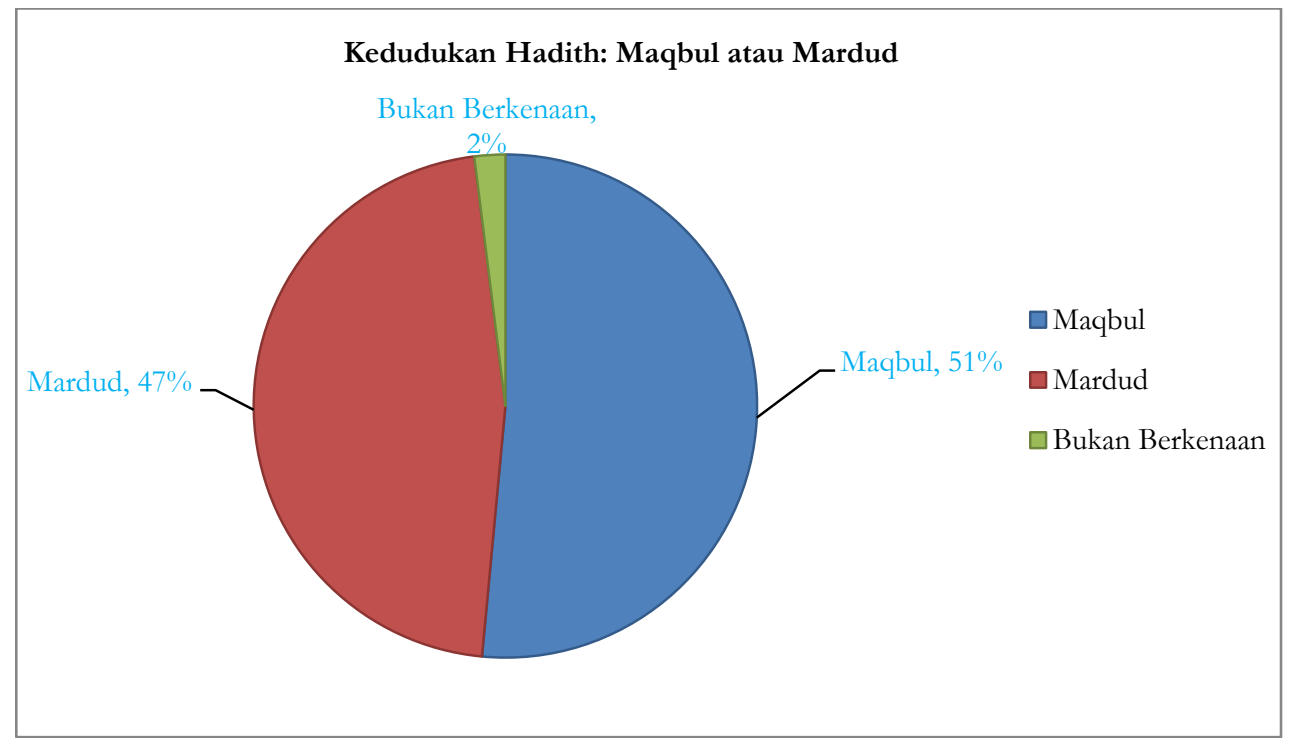

Rajah 1: Peratusan Kedudukan Hadith: Maqbūl atau Mardūd dalam " Kitab Doa Mustajab Harian Yang Dipetik daripada Hadith dan al-Quran.

\section{Hukum Hadith}

(1) Sahỉh dan sabỉh Bukhārīidan Muslim 
Sebahagian besar hadith yang dijadikan doa yang terdapat dalam buku ini adalah hadith Sahih termasuk sabỉh dalam Bukhärī dan Muslim. Pengakaji mendapati terdapat 38 (38\%) hadith sabih yang mana 19 sahih selain Bukhārī dan Muslim dan 19 hadith selain Bukhārī dan Muslim.

(2) Hasan

Terdapat 14 (14\%) hadith hasan. Kebanyakkan hadith bertaraf hasan ini, pengkaji mendapati bahawa hadith asalnya bertaraf da $a^{c} \bar{f}$ yang mempunyai shawāhid dan Mutāba āàt yang mengangkat martabat hadith ini menjadi hasan.

(3) $D a^{c} \bar{i} f$ dan $D a^{c} \ddot{f} J i d d a n$

Terdapat Sebanyak 43 (43\%) hadith daripada 101 hadith dalam kajian ini diklasifikasikan sebagai hadith $d a^{c} \vec{i} f$ dan $4(4 \%)$ hadith yang bertaraf dan $d a^{c} \vec{i}$ Jiddan.

(4) Bukan hadith

Terdapat $2(2 \%)$ buah doa yang terdapat dalam buku ini yang bukan daripada hadith iaitu 1 daripadanya adalah doa yang dinukilkan daripada potongan ayat al-Quran dan 1 daripadanya merupakan daripada sejarah(hikayat) daripada sumber Tārikh Damsyiq oleh Ibn ${ }^{\mathrm{c}}$ Asākir.

Berikut adalah rajah bagi menggambarkan dengan jelas hukum hadith dalam kajian ini: 


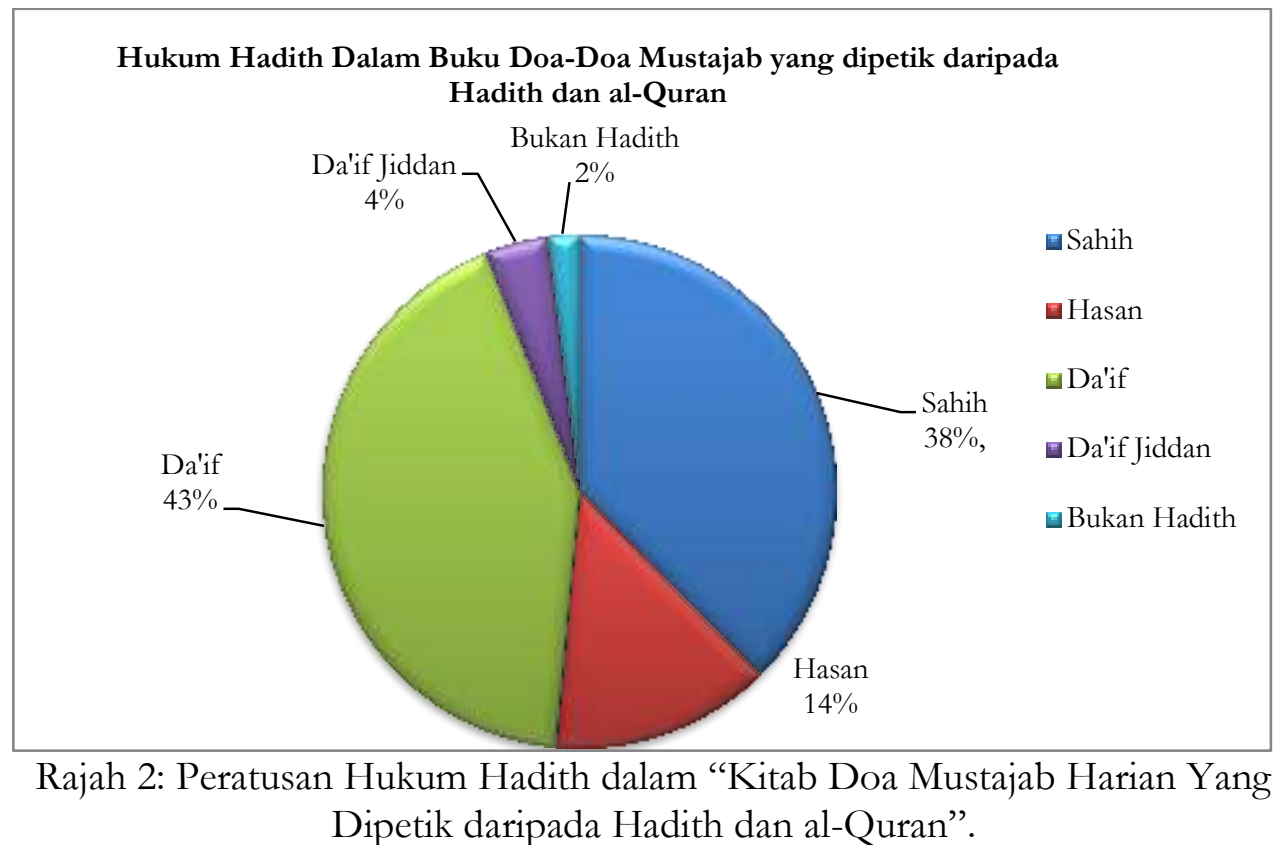

\section{Simpulan}

Setelah melakukan kajian terhadap buku " Doa-Doa Mustajab yang dipetik daripada Hadith dan al-Quran" melalui kaedah takhrij. Keseluruhan kajian mendapati sebanyak $51 \%$ hadith yang maqbūl dan 47\% yang berkedudukan mard $\bar{u} d$ dan $2 \%$ bukan berkenaan.Melalui hasil kajian, cadangan kajian bagi meningkatkan lagi usaha dalam menambahbaikan buku ini melalui beberapa cadangan. Antaranya ialah:

1. Buku ini perlu penambahbaikan dengan menyusun semula kandungan doa supaya dapat dibezakan antara doa yang diambil daripada al-Quran atau hadith dengan meletakkan nama surah serta nombor ayat al-Quran yang diambil.

2. Buku ini juga perlu ditahkrij walaupun secara ringkas dengan meletakkan sumber dan hukum hadith yang dijadikan doa sama ada Sah ih, Hasan, Daij dan meletakkan doa yang sahih sahaja supaya masyarakat dapat menjadikan amalan doa harian dan rujukan.

3. Buku ini perlu ditulis dan dicetak semula dengan versi yang baru serta teknikal bagi menarik masyarakat untuk membaca. 


\section{Daftar Pustaka}

\section{Al-Quran.}

Abu Dayf al-Muduniy.1997. Doa Munajat Para Nabi. Kuala Lumpur: AlHidayah Publisher.

Ahmad Mujahideen Bin Haji Yusoff. 2012. Takhrij dan Táliq Hadis di dalam Kitab 40

Azharuddin Sahil.2002. Doa Makbul atan Tertolak. Kuala Lumpur: Utusan Publications \& Distibutors Sdn Bhd.

Hadis Membudayakan al-Sunnah Siri ke-2. Ijazah Sarjana Pengajian Islam. Bangi: Universiti kebangsaan Malaysia.

Imam Malik. 1985 Muwattā' Imām Mālik. Juz 1. Beirut: Darul Ihyā' Turāth alArabī.

Jawiah Dakir, Budah@Udah Mohsin, Mazlan Ibrahim \& Faisal Ahmad Shah. 2009. Hadith Masybur dalam Masyarakat Melayu: Takhrij dan Analisis. Jurnal Usuluddin. Bil 29 (2009) : 119-146.

Muhammad Abu al-Laith al-Khair Abadi. 2009. Ulum Hadith. Cetakan Pertama. Darul Syakir.

Tafsir kepimpinan al-Rahman. 1983. Tafsir Pimpinan al-Qur'an kepada Pengertian al-Quran. Ed.ke-6. Kuala Lumpur: Dar Fikr: Bahagian Hal Ehwal Islam, Jabatan Perdana Menteri.

Wan Azlee Bin Wan Ibrahim.2014.Kedudukan Hadis dalam Kitab 40 Hadis Membudayakan al-Sunnah (siri ketiga) oleh Jabatan Agama Johor. Ijazah Sarjana Pengajian Islam. Bangi: Universiti kebangsaan Malaysia.

Wan Khairul Aiman Bin Wan Mokhtar. 2012. Takbrij dan Táliq Hadis 40. Membudayakan al-Sunnah Siri ke-4. Ijazah Sarjana Pengajian Islam. Bangi: Universiti kebangsaan Malaysia. 